\title{
The role of animal nutrition in improving the nutritive value of animal-derived foods in relation to chronic disease
}

\author{
D. I. Givens \\ Nutritional Sciences Research Unit, School of Agriculture, Policy and Development, University of Reading, \\ Reading R6 6AR, UK
}

\begin{abstract}
Foods derived from animals are an important source of nutrients in the diet; for example, milk and meat together provide about 60 and $55 \%$ of the dietary intake of $\mathrm{Ca}$ and protein respectively in the UK. However, certain aspects of some animal-derived foods, particularly their fat and saturated fatty acid (SFA) contents, have led to concerns that these foods substantially contribute to the risk of CVD, the metabolic syndrome and other chronic diseases. In most parts of Europe dairy products are the greatest single dietary source of SFA. The fatty acid composition of various animal-derived foods is, however, not constant and can, in many cases, be enhanced by animal nutrition. In particular, milk fat with reduced concentrations of the $\mathrm{C}_{12-16}$ SFA and an increased concentration of 18:1 MUFA is achievable, although enrichment with very-long-chain $n$-3 PUFA is much less efficient. However, there is now evidence that some animal-derived foods (notably milk products) contain compounds that may actively promote long-term health, and research is urgently required to fully characterise the benefits associated with the consumption of these compounds and to understand how the levels in natural foods can be enhanced. It is also vital that the beneficial effects are not inadvertently destroyed in the process of reducing the concentrations of SFA. In the future the role of animal nutrition in creating foods closer to the optimum composition for long-term human health is likely to become increasingly important, but production of such foods on a scale that will substantially affect national diets will require political and financial incentives and great changes in the animal production industry.
\end{abstract}

Chronic disease: Foods from animals: Animal nutrition

The burden of chronic disease is rapidly increasing worldwide. Recent data (World Health Organization/Food and Agriculture Organization, 2003) suggest that in 2001 chronic diseases were responsible for about $60 \%$ of the 56.5 million deaths reported worldwide and about $46 \%$ of the global burden of disease. It has been projected that by 2020 chronic diseases will account for approximately $75 \%$ of all deaths worldwide. Approximately half the total deaths from chronic disease are attributable to CVD, but the rapid increase in the obesity-type 2 diabetes syndrome is particularly worrying, not only because it already affects a large proportion of the population worldwide, but also because it is now starting to affect individuals earlier in life. Also, contrary to popular belief, developing countries are increasingly being affected by chronic disease (World Health Organization, 2002).
It has been known for many years that diet plays a key role as a risk factor for chronic disease. At a global level it is clear that in the second half of the twentieth century there were very major changes to diet in the developed world and, more recently, in developing areas. Often largely plant-based diets have been replaced by an increased consumption of animal products, with a consequent increase in fat content and hence energy density. It is mainly because of the composition of many animal fats that their increased consumption has been associated with increased chronic disease. The present paper will examine the opportunities to improve the composition of animal fats through animal nutrition and will also discuss how these improvements need to be rationalised against other evidence that points to benefits from the consumption of animal-derived foods.

\footnotetext{
Abbreviations: CLA, conjugated linoleic acid; SFA, saturated fatty acids.

Corresponding author: Professor D. I. Givens, fax +44118378, email d.i.givens@reading.ac.uk
} 
Table 1. Trends in consumption of animal products (from World Health Organization/Food and Agriculture Organization, 2003)

\begin{tabular}{|c|c|c|c|c|c|c|}
\hline \multirow[b]{2}{*}{ Region } & \multicolumn{3}{|c|}{ Meat (kg/per capita per year) } & \multicolumn{2}{|c|}{ Milk (kg/per capita per year) } & \multirow[b]{2}{*}{$2030^{*}$} \\
\hline & $1964-6$ & 1977-99 & $2030^{*}$ & $1964-6$ & 1977-99 & \\
\hline World & $24 \cdot 2$ & $36 \cdot 4$ & $45 \cdot 3$ & 73.9 & $78 \cdot 1$ & $89 \cdot 5$ \\
\hline Developing countries & $10 \cdot 2$ & $25 \cdot 5$ & $36 \cdot 7$ & $28 \cdot 0$ & $44 \cdot 6$ & $65 \cdot 8$ \\
\hline Transition countries & $42 \cdot 5$ & $46 \cdot 2$ & $60 \cdot 7$ & $156 \cdot 7$ & $159 \cdot 1$ & $178 \cdot 7$ \\
\hline Industrialised countries & $61 \cdot 5$ & $88 \cdot 2$ & $100 \cdot 1$ & $185 \cdot 5$ & $212 \cdot 2$ & $221 \cdot 0$ \\
\hline
\end{tabular}

*Projected values.

\section{Contribution by animal products to diets}

The demand for animal products is growing globally at a substantial rate, driven by a combination of population growth, urbanisation and rising income. Table 1 shows the trends in meat and milk consumption over the past 40 years for various parts of the world. For large parts of the population animal products represent a source of high-quality protein, but high intakes of particular animal products can lead to excessive fat intakes. From the late 1960s to the late 1990s fat intake per capita rose from 53 to $73 \mathrm{~g} / \mathrm{d}$ worldwide and from 117 to $148 \mathrm{~g} / \mathrm{d}$ within the EU (World Health Organization/Food and Agriculture Organization, 2003). Interestingly, data from the UK National Food Survey (Department for Environment Food and Rural Affairs, 2001) show that over the same period, intakes of total fat and saturated fatty acids (SFA) respectively fell from 120 and $57 \mathrm{~g}$ per capita per d in 1968 to 74 and $29 \mathrm{~g}$ per capita per $\mathrm{d}$ in 2000.

Foods of animal origin make a major contribution to the UK diet. Although in the UK the consumption of whole milk and meat from ruminant animals has declined during recent years, the amounts of skimmed milk and poultry meat in the typical diet have substantially increased (Department for Environment Food and Rural Affairs, 2001). The contribution of various animal-derived foods to key aspects of the UK diet in 2000 (expressed as a percentage of the total dietary intake) is shown in Table 2. These data clearly show that these food sources make a major contribution to protein and $\mathrm{Ca}$ intake and a sizeable contribution to the intake of Fe. As the amount of nutrients derived from eggs and fish and marine products are relatively small, these food sources will not be considered.

Table 2. Contribution (\%) of animal products to mean daily adult intake of energy, protein, fat, calcium and iron in the UK*

\begin{tabular}{lccccc}
\hline Nutrient & $\begin{array}{c}\text { Milk } \\
\text { and } \\
\text { milk } \\
\text { products }\end{array}$ & $\begin{array}{c}\text { Meat } \\
\text { and } \\
\text { meat } \\
\text { products }\end{array}$ & Eggs & $\begin{array}{c}\text { Fish and } \\
\text { fish and } \\
\text { marine } \\
\text { products }\end{array}$ & $\begin{array}{c}\text { Total } \\
\text { excluding } \\
\text { fish }\end{array}$ \\
\hline Energy & 12 & 15 & 2 & 3 & 29 \\
Protein & 16 & 36 & 3 & 7 & 55 \\
Fat & 18 & 23 & 4 & 3 & 45 \\
Ca & 54 & 5 & 1 & 0.4 & 60 \\
Fe & 1.3 & 16 & 2.6 & 0.5 & 20 \\
\hline
\end{tabular}

*Data derived from a combination of the National Food Survey (Department for Environment Food and Rural Affairs, 2001) and Food Standards Agency (2003).
Table 2 also indicates that while the supplies of energy from milk and its products and those from meat are approximately equal, milk is a major source of $\mathrm{Ca}$ and meat (predominantly red meat) makes an important contribution to protein and $\mathrm{Fe}$ in the diet. Overall, animalderived foods contribute about $30 \%$ of the total energy intake, but a high proportion $(0.51)$ of this energy is derived from fat. Since the lipids in milk and dairy products, and to a lesser extent those in the meat of ruminant animals, contain relatively large amounts of SFA (Table 3), these products make a major contribution to SFA intake. A study of fatty acid intake across Europe (Hulshof et al. 1999) has shown that milk and milk products (including cheese and butter) and meat and meat

Table 3. Typical fatty acid composition ( $\mathrm{g} / 100 \mathrm{~g}$ total fatty acids) of fats in animal products (adapted from McCance \& Widdowson, 1998)

\begin{tabular}{|c|c|c|c|}
\hline Fatty acid & Cow's milk & Beef & $\begin{array}{c}\text { Chicken } \\
\text { meat (white) }\end{array}$ \\
\hline $4: 0$ & $3 \cdot 88$ & 0 & 0 \\
\hline $6: 0$ & $2 \cdot 49$ & 0 & 0 \\
\hline $8: 0$ & $1 \cdot 39$ & 0 & 0 \\
\hline $10: 0$ & 3.05 & 0 & 0 \\
\hline $10: 1$ & 0.28 & 0 & 0 \\
\hline $11: 0$ & $1 \cdot 39$ & 0 & 0 \\
\hline $12: 0$ & $4 \cdot 16$ & 0 & 0 \\
\hline $14: 0$ & $11 \cdot 4$ & $2 \cdot 70$ & 0.99 \\
\hline $14: 1(n-5)$ & $1 \cdot 11$ & 0.54 & 0.00 \\
\hline $15: 0$ & $1 \cdot 11$ & 0.54 & $1 \cdot 98$ \\
\hline $16: 0$ & $29 \cdot 4$ & $26 \cdot 2$ & $21 \cdot 8$ \\
\hline $16: 1(n-9)$ & 1.94 & $4 \cdot 05$ & 3.96 \\
\hline $17: 0$ & 0.55 & $1 \cdot 08$ & 0.99 \\
\hline $17: 1$ & 0.28 & $1 \cdot 08$ & 0.99 \\
\hline $18: 0$ & $11 \cdot 4$ & $16 \cdot 0$ & 6.93 \\
\hline $18: 1(n-9)$ & $21 \cdot 9$ & $39 \cdot 7$ & $39 \cdot 6$ \\
\hline $18: 1$ trans $(n-7)$ & 0.28 & 3.51 & 2.97 \\
\hline $18: 2(n-6)$ & 1.94 & $2 \cdot 97$ & $15 \cdot 8$ \\
\hline $18: 3(n-3)$ & 0.55 & $0 \cdot 81$ & 1.98 \\
\hline $20: 0$ & 0.00 & 0.00 & 0.00 \\
\hline $20: 5(n-3)$ & 0.00 & 0.27 & 0.99 \\
\hline $22: 5(n-3)$ & 0.83 & 0.54 & 0.99 \\
\hline \multicolumn{4}{|l|}{ Summary } \\
\hline Total SFA & $70 \cdot 1$ & $46 \cdot 5$ & $32 \cdot 7$ \\
\hline Total MUFA & $25 \cdot 8$ & $48 \cdot 9$ & $47 \cdot 5$ \\
\hline Total PUFA & 3.32 & $4 \cdot 59$ & $19 \cdot 8$ \\
\hline$n-6$ PUFA & 1.94 & 2.97 & $15 \cdot 8$ \\
\hline$n$-3 PUFA & $1 \cdot 39$ & $1 \cdot 62$ & 3.96 \\
\hline
\end{tabular}

SFA, saturated fatty acids. 
products are major sources of SFA in all countries. Dairy products are consistently the greatest source, with the highest intakes being found in Germany and France where approximately $60 \%$ of the SFA intake is derived from this source (in the UK the contribution is approximately $40 \%$ ). Interestingly, the contribution of butter to SFA intake varies widely; in Greece, Spain, The Netherlands and Norway butter provides $>5 \%$ of the SFA intake, in France and Germany the contribution is high (30 and $39 \%$ respectively) and in the UK it is intermediate $(10 \%)$.

\section{Dietary fatty acids and chronic disease}

The relationship between dietary fat type and intake and CVD (particularly CHD) has been extensively investigated, and strong and consistent associations have been reported from a wide body of data (Kris-Etherton et al. 2001). Although SFA generally raise total cholesterol and LDLcholesterol, individual fatty acids in this family have markedly different effects. In particular, myristic acid (14:0) and palmitic acid (16:0) have been associated with elevated plasma LDL-cholesterol concentrations in human subjects (for example, see Katan et al. 1995; Temme et al. 1996), while the other major SFA in foods, stearic acid (18:0), has been shown to be essentially neutral (Bonanome \& Grundy, 1988). Some studies suggest that lauric acid (12:0) and myristic acid exert more potent effects on plasma cholesterol than palmitic acid (Zock et al. 1994), but other research has indicated that myristic acid and palmitic acid are more potent than lauric acid (Denke \& Grundy, 1992). However, palmitic acid is quantitatively the most important SFA in milk and meat fat (Table 3). Most of the lauric acid and myristic acid in the human diet is derived from milk fat (Gunstone et al. 1994), and the consumption of whole milk and dairy products would therefore be expected to have adverse effects on plasma cholesterol levels. The results from a large longitudinal cohort study (Steffen \& Jacobs, 2003) of 2778 black and white men and women, initially aged 18-30 years old, appear to support this concept. In this study diet was assessed over a 7-year period and the various plasma cholesterol fractions measured. Plasma LDL-cholesterol concentrations were found to increase by $0 \cdot 078 \mathrm{mmol} / \mathrm{l}$ across all quintiles of high-fat dairy intake $(P<0 \cdot 05)$, although it was suggested that after correction for within-subject errors in dietary assessment the true mean increase is likely to be three to six times greater $(0 \cdot 26-0 \cdot 47 \mathrm{mmol} / \mathrm{l})$. Furthermore, it was also observed that consumers of low-fat milk have lower HDL-cholesterol levels and consumers of cream and butter have higher HDL-cholesterol levels.

When substituting for SFA in metabolic studies both MUFA and PUFA lower plasma total cholesterol and LDLcholesterol. Although the cholesterol-lowering response to PUFA is greater than that of MUFA, there has been some caution in recommending high-PUFA diets because of potentially-adverse health effects of their lipoperoxidation products (Williams, 2000). Three important $n$-3 PUFA are EPA $(20: 5 n-3)$ and DHA $(22: 6 n-3)$ and $\alpha$-linolenic acid $(18: 3 n-3)$. There is evidence from a range of epidemiological data and from intervention studies in populations at risk of CHD that indicate that EPA and DHA have substantial cardio-protective actions. These data have led to a widespread belief that there should be small increases in n-3 PUFA intake (for details, see Williams, 2000). In general, fats in animal-derived foods are very poor sources of $n-3$ PUFA.

Most of the interest in high intakes of SFA has been focused on the increase in plasma LDL-cholesterol levels and associated increases in CVD risk. However, there is now evidence that high intakes of SFA may also be related to reduced insulin sensitivity, which is a key factor in the development of the metabolic syndrome (Nugent, 2004). In epidemiological studies high intakes of saturated fats have been associated with a higher risk of impaired glucose tolerance and higher fasting plasma glucose and insulin concentrations (Feskens \& Kromhout, 1990; Parker et al. 1993; Feskens et al. 1995). Notably, in a recent 3-month intervention study involving 162 healthy subjects (Vessby et al. 2001) given diets rich in SFA (from butter and margarine) or MUFA (from high-oleic sunflower oil) the subjects on the SFA diet were found to have a markedly impaired insulin sensitivity $(-10 \%)$, while that of the subjects on the MUFA diet was unchanged (Table 4). Furthermore, additional dietary inclusion of $n-3$ fatty acids from fish oil was shown to have no effect on insulin

Table 4. Effect of challenging with saturated fatty acids (SFA) or MUFA on insulin variables, plasma glucose and serum lipids in healthy men and women (from Vessby et al. 2001)

\begin{tabular}{|c|c|c|c|c|c|c|}
\hline \multirow[b]{2}{*}{ Measurement } & \multicolumn{3}{|c|}{ SFA diet } & \multicolumn{3}{|c|}{ MUFA diet } \\
\hline & Change* & $\begin{array}{c}\text { Change } \\
(\%)\end{array}$ & $P$ & Change* & $\begin{array}{c}\text { Change } \\
(\%)\end{array}$ & $P$ \\
\hline Insulin sensitivity index† & $-4 \cdot 2$ & $-10 \cdot 3$ & 0.032 & $+0 \cdot 10$ & $+12 \cdot 1$ & 0.518 \\
\hline Serum insulin (mU/l) & +0.25 & +3.5 & 0.466 & -0.35 & $-5 \cdot 8$ & 0.049 \\
\hline First-phase insulin response $\neq(\mathrm{mU} / \mathrm{l})$ & $+3 \cdot 3$ & $+9 \cdot 0$ & 0.029 & $+3 \cdot 8$ & $+10 \cdot 1$ & $0 \cdot 139$ \\
\hline Plasma glucose $(\mathrm{mmol} / \mathrm{l})$ & 0.00 & 0 & 0.995 & -0.03 & -0.60 & $0 \cdot 413$ \\
\hline Total cholesterol (mmol/l) & $+0 \cdot 14$ & +2.5 & 0.018 & $-0 \cdot 15$ & $-2 \cdot 7$ & 0.012 \\
\hline LDL-cholesterol (mmol/l/) & $+0 \cdot 15$ & $+4 \cdot 1$ & 0.006 & -0.19 & $-5 \cdot 2$ & 0.006 \\
\hline
\end{tabular}

*Mean change during treatment expressed as least square mean.

†One of the four indices produced by the MINMOD model that analyses insulin kinetics following a frequently-sampled intravenous glucose tolerance test (Pacini \& Bergman, 1986).

¥The mean of the insulin concentrations at 2, 4 and 8 min after intravenous glucose dose minus the fasting insulin values (Vessby et al. 2001). 
sensitivity or insulin secretion, and the favourable effects of the MUFA diet were not seen in individuals with a high fat intake ( $>37 \%$ energy intake).

The evidence clearly indicates that SFA intakes need to be reduced and that replacing them with MUFA and PUFA has potential benefits. Given the current contribution that ruminant animal products make to the consumption of SFA, it seems inescapable that the current situation is unsustainable.

\section{Manipulating the fatty acid composition of animal-derived foods}

It is not always recognised that the fatty acid composition of animal-derived foods is not fixed and can vary considerably in response to changes in the diet of productive animals. It follows, therefore, that animal and human nutrition are intimately linked, and current research is actively investigating ways in which milk and meat containing lower concentrations of SFA and enhanced amounts of MUFA and PUFA can be produced, whilst not diminishing the inherent and widely-acclaimed nutritional benefits of these foods.

\section{Manipulating the fatty acid composition of milk}

Milk fat typically contains (g/100 g) 70-75 SFA, 20-25 MUFA and small amounts (2-5) of PUFA (Table 3; Lock $\&$ Shingfield, 2004). Fatty acids secreted in milk originate from two sources, either by direct incorporation from the peripheral circulation or from de novo synthesis in the mammary gland using short-chain $(2: 0$ and $4: 0)$ precursors. Mammary de novo synthesis accounts for all 4:0-12:0, most of the 14:0 and typically about half the 16:0 secreted in milk, while all $\mathrm{C}_{18}$ and longer-chain fatty acids are derived entirely from circulating plasma lipids (Hawke \& Taylor, 1995). A distinctive feature of the bovine mammary gland is its ability to release fatty acids from the synthetase complex at various stages, resulting in the secretion of a wide range of short- and medium-chain fatty acids (Table 3 ). As a result of extensive biohydrogenation of dietary unsaturated fatty acids by rumen bacteria, under most conditions 18:0 is the predominant long-chain fatty acid available for absorption. However, increasing the supply of long-chain fatty acids (of chain length $\geq 18$ ) to the mammary gland inhibits the synthesis of short- and medium-chain SFA (Chilliard et al. 2000). Unlike other ruminant tissues, the mammary gland cannot convert 16:0 to 18:0 by chain elongation (Chilliard et al. 2000). However, it is also notable that the secretion of oleic acid (cis-9-18:1) in milk exceeds its uptake by the mammary gland as a result of the activity of stearoyl-CoA $\left(\Delta^{9}\right)$ desaturase in mammary secretory cells that converts 18:0 to cis-9-18:1 (Kinsella, 1972). Conversion of $18: 0$ to cis-9-18:1 is the predominant precursor-to-product process of the $\Delta^{9}$-desaturase, and about $40 \%$ of the 18:0 taken up by the mammary gland is desaturated (Chilliard et al. 2000).

As a result of the complex process by which milk fatty acids originate, several nutritional approaches can be used to manipulate milk fatty acid composition. Both the amount and source of dietary lipid affect the extent and type of change that can be achieved. A summary of the effects of including various lipids in the diets of dairy cows are reported in Table 5. In general, supplements of plant oils or oilseeds reduce the levels of short- and medium-chain fatty acids in milk but increase those of long-chain fatty acids, resulting in an overall shift towards 18:0 at the expense of 16:0 as a result of decreased de novo synthesis and/or reduced mammary uptake of absorbed 16:0. Reductions in milk SFA content are characterised by small increases in the concentration of the predominant fatty acid in the lipid supplement. In all cases feeding plant oils increases milk fat 18:0, cis-9-18:1 and trans-18:1 contents because of extensive rumen metabolism of long-chain fatty acids, leading to an increased supply of biohydrogenation intermediates (both trans-18:1 and 18:2) and 18:0 to the mammary gland. Table 6 shows the marked decreases in SFA and increases in MUFA observed (Givens et al. 2003) as a result of supplementing dairy cows with cracked whole rapeseed, the oil of which is rich in oleic acid.

PUFA are not synthesised in any appreciable quantities in ruminant tissues, and concentrations in milk are, therefore, essentially a reflection of the amount leaving the rumen. Consequently, oils rich in linoleic acid (18:2n-6)

Table 5. Typical milk fatty acid responses in dairy cows to dietary lipid supplementation (from Givens \& Shingfield, 2003)

\begin{tabular}{|c|c|c|c|c|c|c|c|c|c|c|}
\hline \multirow[b]{2}{*}{ Lipid source } & \multicolumn{10}{|c|}{ Mean response ${ }^{*}$} \\
\hline & $14: 0$ & $16: 0$ & $18: 0$ & $\begin{array}{c}\text { cis-9- } \\
18: 1\end{array}$ & $\begin{array}{c}\text { trans- } \\
18: 1\end{array}$ & $\begin{array}{l}18: 2 \\
(n-6)\end{array}$ & $\begin{array}{l}18: 3 \\
(n-3)\end{array}$ & $\begin{array}{l}\text { Total } \\
\text { SFA }\end{array}$ & MUFA & PUFA \\
\hline Rapeseed oil & -0.03 & -0.20 & 0.55 & 0.39 & 0.30 & -0.09 & $0 \cdot 11$ & -0.07 & 0.30 & -0.04 \\
\hline Rapeseed oil & -0.19 & -0.33 & 0.51 & 0.67 & $2 \cdot 00$ & -0.04 & 0.60 & $-0 \cdot 18$ & 0.60 & 0.15 \\
\hline Soyabean oil & -0.29 & -0.28 & 0.45 & 0.23 & $4 \cdot 61$ & 0.33 & - & $-0 \cdot 19$ & 0.53 & 0.33 \\
\hline Sunflower oil† & -0.32 & -0.32 & 0.14 & 0.27 & 3.07 & -0.05 & -0.24 & -0.22 & 0.53 & 0.12 \\
\hline Sunflower oil & -0.23 & -0.26 & 0.15 & 0.11 & $2 \cdot 79$ & 0.07 & -0.21 & $-0 \cdot 17$ & 0.36 & 0.21 \\
\hline Linseed oil & -0.11 & -0.15 & 0.27 & 0.26 & 0.94 & -0.14 & $0 \cdot 17$ & -0.07 & 0.23 & -0.06 \\
\hline Fish oil & 0.04 & -0.01 & -0.45 & -0.25 & 8.08 & 0.24 & 0.03 & -0.09 & 0.24 & 0.29 \\
\hline Fish oil & 0.30 & 0.35 & -0.77 & -0.73 & $2 \cdot 19$ & 0.39 & 0.07 & -0.05 & $-0 \cdot 10$ & $2 \cdot 17$ \\
\hline Tallow & - & 0.06 & 0.04 & 0.22 & $0 \cdot 19$ & -0.37 & -0.37 & -0.06 & $0 \cdot 19$ & -0.36 \\
\hline
\end{tabular}

SFA, saturated fatty acids.

${ }^{*}$ Responses calculated as proportionate differences between treatment controls and lipid-supplemented diets.

†Sunflower oil rich in cis-9 18:1. 
Table 6. Effect on milk fatty acid composition $(\mathrm{g} / 100 \mathrm{~g}$ total fatty acids) of feeding dairy cows diets containing zero (ZR), medium (MR) and high (HR) inclusion rates of whole cracked rapeseed (from Givens et al. 2003)

\begin{tabular}{|c|c|c|c|}
\hline \multirow[b]{2}{*}{ Fatty acid } & \multicolumn{3}{|c|}{ Treatment $^{*}$} \\
\hline & ZR & MR & $\mathrm{HR}$ \\
\hline $4: 0$ & 4.99 & $3 \cdot 16$ & $2 \cdot 72$ \\
\hline $6: 0$ & $2 \cdot 26$ & $1 \cdot 13$ & 0.96 \\
\hline $8: 0$ & 1.25 & 0.55 & 0.43 \\
\hline 10:0 & 3.07 & $1 \cdot 3$ & 0.98 \\
\hline $10: 1$ & 0.37 & $0 \cdot 13$ & 0.08 \\
\hline $11: 0$ & $0 \cdot 11$ & 0.05 & 0.05 \\
\hline $12: 0$ & 3.95 & $1 \cdot 89$ & $1 \cdot 44$ \\
\hline $14: 0$ & $11 \cdot 6$ & $7 \cdot 85$ & $6 \cdot 0$ \\
\hline $14: 1(n-5)$ & $1 \cdot 4$ & $1 \cdot 15$ & 0.75 \\
\hline $15: 0$ & $2 \cdot 28$ & $1 \cdot 43$ & 0.99 \\
\hline $16: 0$ & $30 \cdot 7$ & $19 \cdot 8$ & $18 \cdot 0$ \\
\hline $16: 1(n-9)$ & 0.18 & 0.23 & 0.26 \\
\hline $16: 1(n-7)$ & 1.92 & $1 \cdot 83$ & 1.58 \\
\hline $17: 0$ & $1 \cdot 63$ & $1 \cdot 16$ & 0.89 \\
\hline $17: 1$ & 0.31 & 0.22 & $0 \cdot 18$ \\
\hline $18: 0$ & $8 \cdot 3$ & $14 \cdot 1$ & $15 \cdot 8$ \\
\hline $18: 1(n-9)$ & $18 \cdot 1$ & $34 \cdot 7$ & $39 \cdot 3$ \\
\hline 18: 1 trans $(n-7)$ & 1.97 & $2 \cdot 58$ & $2 \cdot 03$ \\
\hline $18: 2(n-6)$ & $2 \cdot 08$ & $2 \cdot 37$ & $2 \cdot 76$ \\
\hline 18:2 (conjugated) & $0 \cdot 60$ & 1.02 & 0.74 \\
\hline $18: 3(n-3)$ & 0.45 & 0.48 & 0.60 \\
\hline $20: 0$ & $0 \cdot 13$ & 0.27 & $0 \cdot 30$ \\
\hline Others & $0 \cdot 74$ & $1 \cdot 13$ & 1.29 \\
\hline \multicolumn{4}{|l|}{ Summary } \\
\hline Total SFA & $70 \cdot 6$ & $52 \cdot 8$ & $48 \cdot 6$ \\
\hline Total MUFA & $24 \cdot 2$ & $40 \cdot 8$ & $44 \cdot 2$ \\
\hline Total PUFA & $3 \cdot 13$ & 3.87 & $4 \cdot 1$ \\
\hline
\end{tabular}

SFA, saturated fatty acids.

All treatment effects were significant: ${ }^{\star} P<0.05$

and $\alpha$-linolenic acid $(18: 3 n-3)$ have been used to increase the concentrations of these PUFA in milk or ruminant meat. In addition, the potential to enhance the concentrations of the long-chain $n-3$ PUFA, EPA $(20: 5 n-3)$ and DHA (22:6n-3), in milk (and beef) have been examined, typically using fish oil as a source of EPA and DHA. However, the transfer efficiency of EPA and DHA from the diet into milk is very low because of extensive biohydrogenation in the rumen and subsequent transport of absorbed $n$ - 3 PUFA in phospholipid and cholesteryl ester fractions of plasma that are poorly utilised by the mammary gland (Rymer et al. 2003). In addition, inclusion of fish oil in the diets of dairy cows reduces levels of 18:0 and markedly increases the amounts of trans-18:1 and trans-18:2 in milk (Shingfield et al. 2003). The effects of reducing the extent of saturation of fatty acids in dairy products have been demonstrated in an 8-week study (Noakes et al. 1996) of thirty-three men and women in which the effects of fatty acid-modified and normal dairy products were compared. The modified products were found to result in a marked reduction in total cholesterol $(0.28 \mathrm{mmol} / \mathrm{l})$ and LDLcholesterol $(0.24 \mathrm{mmol} / \mathrm{l})$, with HDL-cholesterol being unaffected. The authors suggest that if these changes were to be applied to Western populations they would represent a potential strategy for lowering the risk of CHD without the need to change normal eating patterns.

There has also been much recent research aimed at increasing the conjugated linoleic acid (CLA) concentration in milk fat because of its potentially powerful anticancer effect. CLA is a generic term used to describe a mixture of geometric and positional isomers of $18: 2$ that contain a conjugated double bond. There is now increasing evidence, based on studies in rodent models, that cis-9, trans-11-CLA exhibits anti-carcinogenic properties (Parodi, 2003), although there is currently no convincing evidence from human studies. Dairy products are the major source of CLA in the human diet (Lawson et al. 2001), and the cis-9, trans-11-isomer is the most abundant isomer in ruminant-derived foods. A number of nutritional strategies involving extended grazing or lipid supplementation have been developed to enhance CLA concentrations in milk, and it has been shown that concentrations of CLA are higher in milk fat from cows offered fresh forages as compared with conserved forages, and they can also be enhanced using whole oilseeds or oil supplements in the cow's diet (Griinari \& Bauman, 1999). Fish oil has been shown to increase the CLA content of milk fat more effectively than plant oils (Chilliard et al. 2000), and these responses can be further enhanced when fish oil is fed in combination with 18:2-rich supplements (for a fuller discussion on CLA enrichment, see Givens \& Shingfield, 2004).

\section{Manipulating the fatty acid composition of meat}

In general, fat in meats derived from ruminant animals is composed of $(\mathrm{g} / 100 \mathrm{~g})$ approximately 45-55 SFA, 45-50 MUFA and relatively minor amounts of PUFA (Table 3; Mir et al. 2003). Much of the effort in manipulating the fatty acid composition of beef, and to a lesser extent lamb, has been directed towards increasing PUFA:SFA and enhancing $n$-3 PUFA: $n-6$ PUFA. The most effective means of manipulating the fatty acid composition of beef is through nutrition, using high-forage-based diets or oil supplements rich in PUFA. In northern Europe an important feed for beef cattle is fresh grass, which has a number of benefits because the major fatty acid in grass is $\alpha$-linolenic acid (Dewhurst et al. 2003). Even though most of the $\alpha$-linolenic acid is hydrogenated in the rumen, a small proportion of it can escape and, once absorbed, is available for incorporation into tissue lipids.

In contrast, the fatty acid profile of non-ruminant meat is essentially a reflection of that in the diet, since limited transformation of dietary fatty acids occurs during digestion and absorption. Accordingly, it is theoretically easier to enhance long-chain $n$-3 PUFA levels in non-ruminant tissue lipids using dietary sources. Since little transformation of dietary $\alpha$-linolenic acid to EPA and DHA occurs in pig and poultry tissues, enrichment in EPA and DHA has therefore relied heavily on dietary supplements of fish oil (Table 7). Whilst this nutritional strategy is relatively effective it can result in the production of meat with a metallic taint, fish-like flavour and reduced shelf-life (Leskanich \& Noble, 1997). One of the key challenges ahead is to identify novel alternative sources of EPA and DHA. 
Table 7. The effect of including fish oil in the diet of broilers on selected fatty acids ( $\mathrm{g} / 100 \mathrm{~g}$ total carcass lipids) in the thigh meat (from Lopez-Ferrer et al. 2001)

\begin{tabular}{lccc}
\hline & \multicolumn{3}{c}{ Dietary inclusion rate of fish oil $(\mathrm{g} / \mathrm{kg})$} \\
\cline { 2 - 4 } Fatty acid & 0 & 20 & 40 \\
\hline $14: 0$ & $0 \cdot 77$ & $1 \cdot 26$ & $1 \cdot 47$ \\
$16: 0$ & $33 \cdot 8$ & $32 \cdot 1$ & $29 \cdot 0$ \\
$18: 0$ & $8 \cdot 54$ & $9 \cdot 42$ & $8 \cdot 54$ \\
$18: 1 n-9$ & $34 \cdot 7$ & $31 \cdot 8$ & $29 \cdot 3$ \\
$18: 2 n-6$ & $11 \cdot 7$ & $11 \cdot 4$ & $12 \cdot 9$ \\
$18: 3 n-3$ & $1 \cdot 63$ & $2 \cdot 46$ & $2 \cdot 98$ \\
$20: 5 n-3$ & $0 \cdot 20$ & $0 \cdot 77$ & $1 \cdot 33$ \\
$22: 6 n-3$ & $0 \cdot 10$ & $1 \cdot 03$ & $2 \cdot 42$ \\
Total SFA & $43 \cdot 8$ & $43 \cdot 6$ & $39 \cdot 8$ \\
Total MUFA & $41 \cdot 3$ & $38 \cdot 7$ & $37 \cdot 6$ \\
Total PUFA & $14 \cdot 9$ & $17 \cdot 5$ & $22 \cdot 2$ \\
$n-6: n-3$ & $6 \cdot 11$ & $2 \cdot 50$ & $1 \cdot 73$ \\
\hline
\end{tabular}

SFA, saturated fatty acids.

\section{Other considerations}

Whilst there is now much evidence to show that it may be possible to improve the lipid profile of animal-derived foods, there are also some serious concerns. A recent prospective study (Ness et al. 2001) over a period of 25 years has indicated that increased consumption of milk is associated with a substantially-reduced risk of death from CVD, particularly CHD (Fig. 1), and the authors refer to a number of similar studies that support their findings. A number of factors have been proposed for the apparent protective effect of milk. For example, although 12:0, 14:0 and 16:0 fatty acids increase serum LDL-cholesterol when substituted for 18:1 (or carbohydrate), they also increase the concentration of HDL-cholesterol, with 14:0 possibly producing the greatest increase (for example, see Temme et al. 1996). This finding, together with the view of some scientists that serum HDL-cholesterol better discriminates between subjects at risk of CHD than total cholesterol or LDL-cholesterol (Rubins et al. 1995), gives rise to doubts about the benefits of reducing the SFA content of foods.

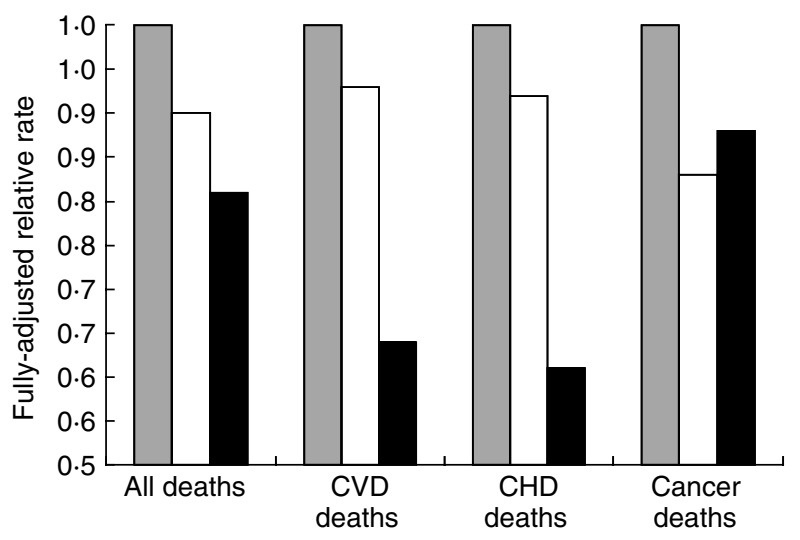

Fig. 1. Relative mortality rate ( 25 years) in 5765 men according to level of milk consumption: $(\square)$, very low; $(\square)$, moderate; $(\mathbf{\square})$, high. (From Ness et al. 2001.)
Furthermore, Samuelson et al. (2001) have reported an unexpected inverse association between dietary SFA and serum cholesterol in adolescents whose dietary source of SFA is mainly milk fat, and have suggested that milk fat may contain or be associated with some component that counterbalances the expected positive relationship between SFA and plasma lipids. These findings are essentially in agreement with those of Smedman et al. (1999) that in 70-year-old men there are negative relationships between the intake of milk products and a number of variables, including LDL-cholesterol:HDL-cholesterol, BMI and waist circumference, but positive relationships with HDLcholesterol and apoA-I.

Furthermore, a US study (Pereira et al. 2002) involving a total of 3157 young adults has shown that increased consumption of dairy products over a 10-year period appears to protect overweight individuals $\left(B M I \geq 25 \mathrm{~kg} / \mathrm{m}^{2}\right.$ ) from the development of obesity and insulin resistance (Fig. 2). The authors have proposed a number of possible reasons for the observations, including a protective effect of milk $\mathrm{Ca}$ and the low glycaemic index associated with dairy products. Although this study was observational, it is of great interest. More recently, Wijga et al. (2003), in a study involving 2978 preschool children, have shown that frequent consumption of whole milk is associated with a reduced prevalence of asthma and daily consumption of butter produces an even lower prevalence.

There has also been much speculation about the possibility that consumption of dairy products can give protection from various cancers. A review of the evidence (Norat \& Riboli, 2003) indicates that data from cohort studies support the hypothesis of a protective effect of total dairy product consumption and milk against colo-rectal cancer. It has been suggested that milk fat contains potential anticancer agents, including CLA, sphingolipids and butyrate (for review, see Parodi, 2003). It is notable that a number of studies in animal models have shown that milk-derived sphingomyelin reduces colon tumour development (Schmelz et al. 2000). Overall, it seems that milk fat contains, or is associated with, components that counterbalance the expected negative effects of SFA. All these issues need investigation at the mechanistic level.

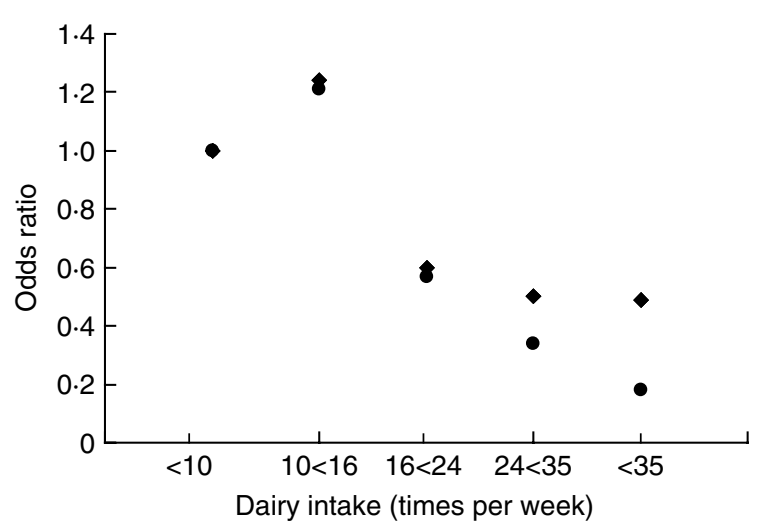

Fig. 2. Adjusted odds ratio for the incidence of insulin resistance relative to intake of dairy products. $(\bullet)$, Men; $(\bullet)$, women. (From Pereira et al. 2002.) 
It is also known that milk proteins are potentially very good sources of bioactive peptides. These peptides have a range of activities, including angiotensin-converting enzyme inhibition and hence a blood pressure-reducing effect (Korhonen \& Pihlanto, 2003). All these potentially very powerful opportunities must be explored.

\section{Conclusions}

Foods derived from animals are an important source of nutrients in the diet. However, certain aspects of some animal-derived foods, particularly SFA, have led to concerns about the contribution of these foods to increased risk of CVD and the metabolic syndrome. The fatty acid composition of various animal-derived foods is not constant and can, in many cases, be enhanced by animal nutrition. In the future, the role of animal nutrition in creating foods closer to the optimum composition for long-term human health will become increasingly important. However, certain animal-derived foods contain compounds that may actively promote long-term health, and research is urgently required to fully characterise the benefits associated with the consumption of these compounds and to understand how the levels in natural foods can be enhanced. It is also vital that the beneficial effects are not inadvertently destroyed in the process of reducing the concentrations of SFA. Although SFA have clearly been shown to increase LDL-cholesterol, the effects of consumption of milk fat and dairy products on the risk of CVD and other chronic diseases are clearly complex. Research is urgently needed to resolve this issue. It should also be noted that the production of improved animal-derived foods on a scale that will substantially affect national diets will require both substantial political and financial incentives and great changes in the animal production industry.

\section{Acknowledgments}

The author's research is supported by LIPGENE, an Integrated Project within the EU funded Sixth Framework Research programme (see www.lipgene.tcd.ie).

\section{References}

Bonanome A \& Grundy SM (1988) Effect of dietary stearic acid on plasma cholesterol and lipoprotein. New England Journal of Medicine 318, 1244-1248.

Chilliard Y, Ferlay A, Mansbridge RM \& Doreau M (2000) Ruminant milk fat plasticity: nutritional control of saturated, polyunsaturated, trans and conjugated fatty acids. Annales de Zootechnie 49, 181-205.

Denke MA \& Grundy SM (1992) Comparison of effects of lauric acid and palmitic acid on plasma lipids and lipoproteins. American Journal of Clinical Nutrition 56, 895-898.

Department for Environment Food and Rural Affairs (2001) The National Food Survey. London: The Stationery Office; available at www.defra.gov.uk/esg/m_natstats.htm

Dewhurst RJ, Scollan ND, Lee MRF, Ougham HJ \& Humphreys MO (2003) Forage breeding and management to increase the beneficial fatty acid content of ruminant products. Proceedings of the Nutrition Society 62, 329-336.
Feskens EJM \& Kromhout D (1990) Habitual dietary intake and glucose tolerance in euglycaemic men: the Zutphen Study. International Journal of Epidemiology 19, 953-959.

Feskens EJM, Virtanen SM, Rasanen L, Tuomilehto J, Stengard J, Pekkanen J, Nissinen A \& Kromhout DA (1995) 20-year follow-up of the Finnish and Dutch cohorts of the Seven Countries Study. Diabetes Care 18, 1104-1112.

Food Standards Agency (2003) National Diet and Nutrition Survey: Adults Aged 16 to 64 Years, vol. 2. Newport, Gwent: Office for National Statistics.

Givens DI, Allison R \& Blake JS (2003) Enhancement of oleic acid and vitamin $\mathrm{E}$ concentrations of bovine milk using dietary supplements of whole rapeseed and vitamin E. Animal Research 52, 531-542.

Givens DI \& Shingfield KJ (2003) Improving the nutritional quality of milk. In Dairy Processing, Improving Quality, pp. 515-531 [G Smit, editor]. Cambridge: Woodhead Publishing Ltd.

Givens DI \& Shingfield KJ (2004) Foods derived from animals: the impact of animal nutrition on their nutritive value and ability to sustain long term health. Nutrition Bulletin 29, 325-332.

Griinari JM \& Bauman DE (1999) Biosynthesis of conjugated linoleic acid and its incorporation into meat and milk in ruminants. In Advances in Conjugated Linoleic Acid Research, vol. 1, pp. 180-200 [MP Yurawecz, MM Mossoba, JKG Kramer, MW Pariza and GJ Nelson, editors]. Champaign, IL: AOCS Press.

Gunstone FD, Harwood JL \& Padley FP (1994) Occurrence and characteristics of oils and fats. In The Lipid Handbook, pp. 47-224 [FD Padley, FD Gunstone and JL Harwood, editors]. Cambridge: The University Press.

Hawke TW \& Taylor JC (1995) Influence of nutritional factors on the yield, composition and physical properties of milk fat. In Advanced Dairy Chemistry. vol. 2: Lipids, pp. 37-88 [PF Fox, editor]. London: Chapman and Hall.

Hulshof KFAM, van Erp-Baart MA, Anttolainen M, Becker W, Church SM, Couet C et al. (1999) Intake of fatty acids in Western Europe with emphasis on trans fatty acids: The TRANSFAIR study. European Journal of Clinical Nutrition 53, 143-157.

Katan MB, Zock PL \& Mensink RP (1995) Dietary oils, serum lipoproteins, and coronary heart disease. American Journal of Clinical Nutrition 61, 1368S-1373S.

Kinsella JE (1972) Stearyl CoA as a precursor of oleic acid and glycerolipids in mammary microsomes from lactating bovine: possible regulatory step in milk triglyceride synthesis. Lipids $\mathbf{7}$, 349-355.

Korhonen H \& Pihlanto A (2003) Bioactive peptides: new challenges and opportunities for the dairy industry. Australian Journal of Dairy Technology 58, 129-134.

Kris-Etherton PM, Daniels SR, Eckel RH, Engler M, Howard BV, Krauss RM, Lichtenstein AH, Sacks F, St Jeor S \& Stampfer M (2001) Summary of the scientific conference on dietary fatty acids and cardiovascular health: conference summary from the nutrition committee of the American Heart Association. Circulation 103, 1034-1039.

Lawson RE, Moss AR \& Givens DI (2001) The role of dairy products in supplying conjugated linoleic acid to man's diet: a review. Nutrition Research Reviews 14, 153-172.

Leskanich CO \& Noble RC (1997) Manipulation of the $n-3$ polyunsaturated fatty acid composition of avian eggs and meat. World's Poultry Science Journal 53, 155-183.

Lock AL \& Shingfield KJ (2004) Optimising milk composition. In Dairying-Using Science to Meet Consumers' Needs. British Society of Animal Science, Publication no. 29, pp. 107-188 [E Kebreab, J Mills and DE Beever, editors]. Loughborough, Leics.: Nottingham University Press. 
López-Ferrer S, Baucells MD, Barroeta AC, Galobart J \& Grashorn MA (2001) n-3 enrichment of chicken meat. 2. Use of very long-chain fatty acids in chicken diets and their influence on meat quality: fish oil. Poultry Science 80, 741-752.

McCance RA \& Widdowson EM (1998) Fatty Acids. Seventh Supplement to the 5th Edition of the Composition of Foods. Cambridge: The Royal Society of Chemistry and MAFF.

Mir PS, Ivan M, He ML Pink B, Okine E, Goonewardene L, McAllister TA, Weselake R \& Mir Z (2003) Dietary manipulation to increase conjugated linoleic acids and other desirable fatty acids in beef: A review. Canadian Journal of Animal Science 83, 673-685.

Ness AR, Smith GD \& Hart C (2001) Milk, coronary heart disease and mortality. Journal of Epidemiology and Cоттиnity Health 55, 379-382.

Noakes M, Nestel PJ \& Clifton PM (1996) Modifying the fatty acid profile of dairy products through feedlot technology lowers plasma cholesterol of humans consuming the products. American Journal of Clinical Nutrition 63, 42-46.

Norat T \& Riboli E (2003) Dairy products and cancer. A review of possible mechanisms and epidemiological evidence. European Journal of Clinical Nutrition 57, 1-17.

Nugent AP (2004) The metabolic syndrome. Nutrition Bulletin 29, 36-43.

Pacini G \& Bergman RN (1986) MINMOD: a computer program to calculate insulin sensitivity and pancreatic responsivity from frequently sampled intravenous glucose tolerance test. Computer Methods and Programs in Biomedicine 23, 113-122.

Parker DR, Weiss ST, Troisi R, Cassano PA, Vokonas PS \& Landsberg L (1993) Relationship of dietary saturated fatty acids and body habitus to serum insulin concentrations: the Normative Aging Study. American Journal of Clinical Nutrition 58, 129-136.

Parodi PW (2003) Anti-cancer agents in milk fat. Australian Journal of Dairy Technology 58, 114-118.

Pereira MA, Jacobs DR, Van Horn L, Slattery ML, Kartashhov AI \& Ludwig DS (2002) Dairy consumption, obesity, and the insulin resistance syndrome in young adults, The CARDIA study. Journal of the American Medical Association 287, 2081-2089.

Rubins HB, Robins SJ, Collins D, Iranmanesh A, Wilt TJ, Mann MD et al. (1995) Distribution of lipids in 8500 men with coronary heart disease. American Journal of Cardiology 75, $1196-1201$.

Rymer C, Givens DI \& Wahle KWJ (2003) Dietary strategies for increasing docosahexaenoic acid (DHA) and eicosapentaenoic acid (EPA) concentrations in bovine milk: a review. Nutrition Abstracts and Reviews 73B, 9R-25R.

Samuelson G, Bratteby L-E, Mohsen R \& Vessby B (2001) Dietary fat intake in healthy adolescents: inverse relationships between the estimated intake of saturated fatty acids and serum cholesterol. British Journal of Nutrition 85, 333-341.

Schmelz E-M, Sullards MC, Dillehay DL \& Merrill AH (2000) Colonic cell proliferation and aberrant crypt foci formation are inhibited by dairy glycosphingolipids in 1, 2-dimethylhydrazine-treated CF1 mice. Journal of Nutrition 130, 522-527.

Shingfield KJ, Ahvenjärvi S, Toivonen V, Ärölä A, Nurmela KVV, Huhtanen P \& Griinari JM (2003) Effect of fish oil on biohydrogenation of fatty acids and milk fatty acid content in cows. Animal Science 77, 165-179.

Smedman AEM, Gustafsson I-B, Berglund LGT \& Vessby BOH (1999) Pentadecanoic acid (C15:0) in serum as a marker for intake of milk fat. The relationships between the intake of milk fat and metabolic risk factors. American Journal of Clinical Nutrition 69, 22-29.

Steffen LM \& Jacobs DR (2003) Relation between dairy food intake and plasma lipid levels: the CARDIA Study. Australian Journal of Dairy Technology 58, 92-97.

Temme EHM, Mensink, RP \& Hornstra G (1996) Comparison of the effects of diets enriched in lauric, palmitic, or oleic acids on serum lipids and lipoproteins in healthy women and men. American Journal of Clinical Nutrition 63, 897-903.

Vessby B, Uusitupa M, Hermansen K, Riccardi G, Rivellese AA, Tapsell LC et al. (2001) Substituting dietary saturated for monounsaturated fat impairs insulin sensitivity in healthy men and women. Diabetologia 44, 312-319.

Wijga AH, Smit HA, Kerkhof M, de Jongate JC, Gerritsen J, Neijens HJ, Boshuizen HC \& Brunekreef B (2003) Association of consumption of products containing milk fat with reduced asthma risk in pre-school children: the PIAMA birth cohort study. Thorax 58, 567-572.

Williams CM (2000) Dietary fatty acids and human health Annals de Zootechnie 49, 165-180.

World Health Organization (2002) Diet, Physical Activity and Health. WHO Documents A55/16 and A55/16 Cor.1. Geneva: WHO.

World Health Organization/Food and Agriculture Organization (2003) Diet, Nutrition and the Prevention of Chronic Diseases. Report of a Joint WHO/FAO Expert Consultation. Geneva: WHO.

Zock PL, de Vries JH \& Katan MB (1994) Impact of myristic acid versus palmitic acid on serum lipid and lipoprotein levels in healthy women and men. Arteriosclerosis and Thrombosis $14,567-575$. 